\title{
DEINOCOCCUS RADIODURANS: EM BUSCA DA ELUCIDAÇÃO DE MECANISMOS DE RADIOPROTEÇÃO
}

\author{
Akíria Torreão ${ }^{1 *}$, Dayane Barboza ${ }^{1}$, Larissa Lino ${ }^{1}$, Willys Candido¹, Gabriel Guimarães ${ }^{1}$, Paulo Filho¹, Jonas Filho ${ }^{1}$, \\ Isvânia Lopes ${ }^{1}$ \\ ${ }^{1}$ Laboratório de Biofísica Celular e Molecular, UFPE \\ *akiria.ohana@ufpe.br
}

\section{RESUMO}

Deinococcus radiodurans é uma bactéria gram-positiva extremófila, não patogênica, não formadora de esporos e que tem se mostrado altamente resistente à radiação ionizante, estresse oxidativo, dessecação e outras condições danosas, sendo capaz de sobreviver a doses extremas de radiação, 1000 vezes maior do que a maioria dos vertebrados (PEANA et al., 2016; MUNTEANU et al., 2015; BRUHN et al., 2009; SAITO; FUJII, 2014; PELLEGRINO et al., 2012). Além disso, o D. radiodurans se revelou, em simulações feitas em aceleradores de partículas, capaz de suportar viagens pelo espaço em fragmentos de poeira (PAULINO-LIMA et al., 2011) e mostrou-se resistente em condições inóspitas, características das regiões próximas a estrelas e planetas (KRAL et al., 2011). Essa bactéria pode suportar temperaturas acima dos $39^{\circ} \mathrm{C}$, e foi testada em meios com elevadas concentrações de sulfato de magnésio e de ácido sulfúrico (SLADE \& RADMAN, 2011), condições que são esperadas em Europa, satélite natural do planeta Júpiter; aos quais sobreviveu (PAVLOV et al., 2018; ABREVAYA et al., 2011). Com o advento da exploração espacial, assim como o uso crescente de radiação pela humanidade, tanto para fins bélicos (CARL;
SVIREZHEV; STENCHIKOV, 2008), quanto de geração de energia e tecnológicos (YEONG; CHENG; NG, 2014); tem-se buscado mecanismos de proteção contra a mesma (PRAZDNOVA et al.,2014), com isso o presente trabalho tem por objetivo revisar o que há na literatura corrente em relação à radiorresistência da Deinococcus radiodurans visto que este microrganismo é um dos mais resistentes à radiação e que sua pesquisa pode contribuir para desenvolver mecanismos de radioproteção. Para isso foi realizado uma revisão bibliográfica nas principais bases de dados "Science Direct", “Medline", "Scorpus", "Scielo" num período de 20092019, o critério de inclusão foram artigos publicado na língua inglesa, usando os seguintes descritores "Ionizing radiation and Deinococcus radiodurans" e "Radioresistant of Deinococcus radiodurans". Foram baixados um total de 218 artigos dos quais foram excluídos artigos repetidos, revisões e os que fugiam ao tema, foi possível notar que o Deinococcus tem mostrado ser um potencial objeto de estudo para desenvolver tecnologias de radioproteção, sendo seu mecanismo de reparo o maior foco de pesquisa. 